\title{
How CARES of Farmington Hills, Michigan, responded to the COVID-19 pandemic
}

\author{
Thomas Schoenfeldt * \\ CARES of Farmington Hills
}
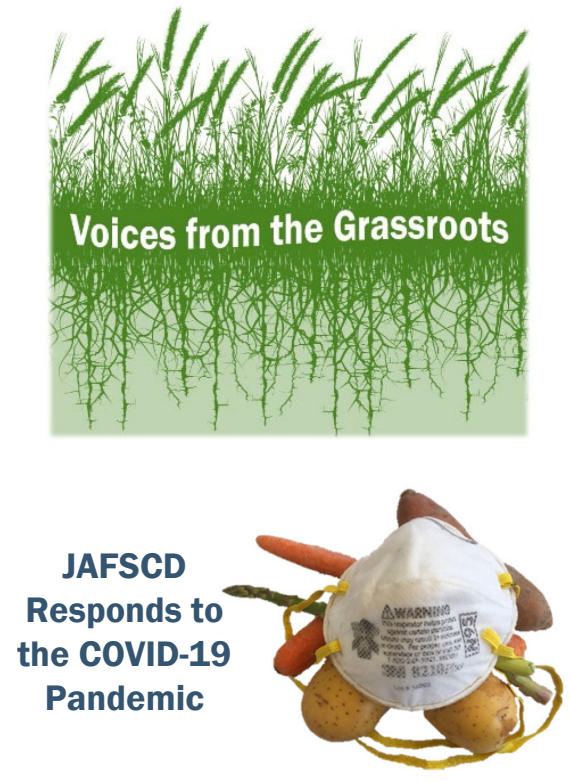

Submitted September 14, 2020 / Published online October 13, 2020

Citation: Schoenfeldt, T. (2020). How CARES of Farmington Hills, Michigan, responded to the COVID-19 pandemic. Journal of Agriculture, Food Systems, and Community Development, 10(1), 9-11. https://doi.org/10.5304/jafscd.2020.101.002

Copyright (C) 2020 by the Authors. Published by the Lyson Center for Civic Agriculture and Food Systems. Open access under CC-BY license.

C ARES of Farmington Hills (Michigan) is a front-line food pantry that serves nine cities. CARES is a 501(c)(3) nonprofit. Prior to the COVID-19 pandemic, the CARES office included a large meeting area, clothing room, and the food pantry. Before the pandemic arrived, it was a clientchoice, self-serve food pantry set up like a grocery store that is available to those in need in the service area. The pantry was open five days a week, and shopping was available by appointment. Each guest can visit the pantry once each month, and no guest is ever turned away. If a guest is not in our service area, they are offered an emergency bag that consists of enough food for a couple of days and are given a list of food pantries near them. At the beginning of the pandemic, we were serving 400 to 500 families each month.

When the pandemic struck, the client-choice

\footnotetext{
* Thomas Schoenfeldt is a volunteer food procurement manager at CARES of Farmington Hills, Michigan. He can be reached at organictom1946@gmail.com. CARES is at http://caresfh.org/
}

pantry and other areas in the building were cleared out to allow pallets of food to be stored so they could be used in a bag-packing process. The entire distribution process changed to a drive-up system, where carts of food were unloaded into each guest's trunk with no personal contact. We were complying with the recommendations of a variety of health organizations throughout the region and state by doing this.

The structure and requirements for volunteers also completely changed. We now had teams from local churches come in to help pack bags of nonperishable products for distribution. Two different bags of nonperishable products were prepared in separate rooms to maintain spacing and limit exposure. In response to the pandemic, we dismantled the meeting room to make it into two areas for packing bags, with pallets of food and tables spaced out as required for social distancing. The shelves of the client-choice pantry area were emptied to create a third bag-packing area as well as to store dry goods. Volunteer changes were also major. Before the pandemic, there were clothing 
volunteers, check-in volunteers, check-out volunteers, and stockers. The pandemic created the need for bag-packing teams, loaders for the cars, traffic directors, cart fillers, and runners for the frozen meats. Most of the volunteers adapted well to the new situation, realizing it was out of our control. The shifts were expanded for the loaders, as these were younger volunteers, and they worked all of the distribution days, thus limiting exposure of our more vulnerable volunteers to the virus.

During the pandemic, we contacted food companies seeking donated foods to help those in need. We were able to build a relationship with a produce supplier and a chicken farm, so we got a pallet of eggs (900 dozen) and all the produce (peppers, cucumbers, and tomatoes) we need for the distributions each month. We were able to make arrangements to get the USDA boxes of food (produce, dairy, cheese, meat, and nonperishables) for distribution as well. By working with the food suppliers, we were able to keep the growth in food costs to a minimum as all of the food from the food suppliers and the USDA boxes were provided at no cost to the pantry. A local institutional food supplier allowed one of its refrigerator/ freezer trailers to be parked at CARES for 7 weeks, and it filled the trailer twice with products to be given away as well as serving as storage for donations from other food suppliers.

During the pandemic we have had only four distribution days each month, as we have to pack bags and clean on other days. On a distribution day, volunteers filled shopping carts with the USDA boxes, several dozen eggs, a case of produce, and two bags of nonperishable food from CARES. As the cars were being loaded from the shopping cart, the car driver let a volunteer know what meat choices they would prefer and that volunteer went to the freezer and collected the meat and placed it in the trunk of the car, after which the guest could drive away. The traffic situations were managed by setting appointments for the pickups. A group of volunteers was also used to help direct traffic. This seemed to work very well; we received no complaints from the neighbors living nearby.

In the month of June 2020, we served 1,394 families, and the weight of the food distributed was more than 70,000 pounds. Obtaining some grants and building relationships with the food suppliers helped significantly in reducing the cost of food that would have had to be purchased from the food banks. The food budget for this pantry was normally US $\$ 7,000$ to US $\$ 8,000$ each month from the local food banks. From March 2020 through June 2020, the amount of money that had to be spent on food was about US\$3,000 in total. This shows real results of some small grants as well as food company relationships, which will continue after the pandemic.

Another big thing that CARES of Farmington Hills was able to accomplish was getting licensed as a Bridge Card store. This lets us accept Bridge Cards (Michigan's version of SNAP EBT, “food stamps" electronic benefits transfer payments) as payment. The clothing room was converted into the new SNAP store. We are able to buy food from food companies and distributors so we have a well-

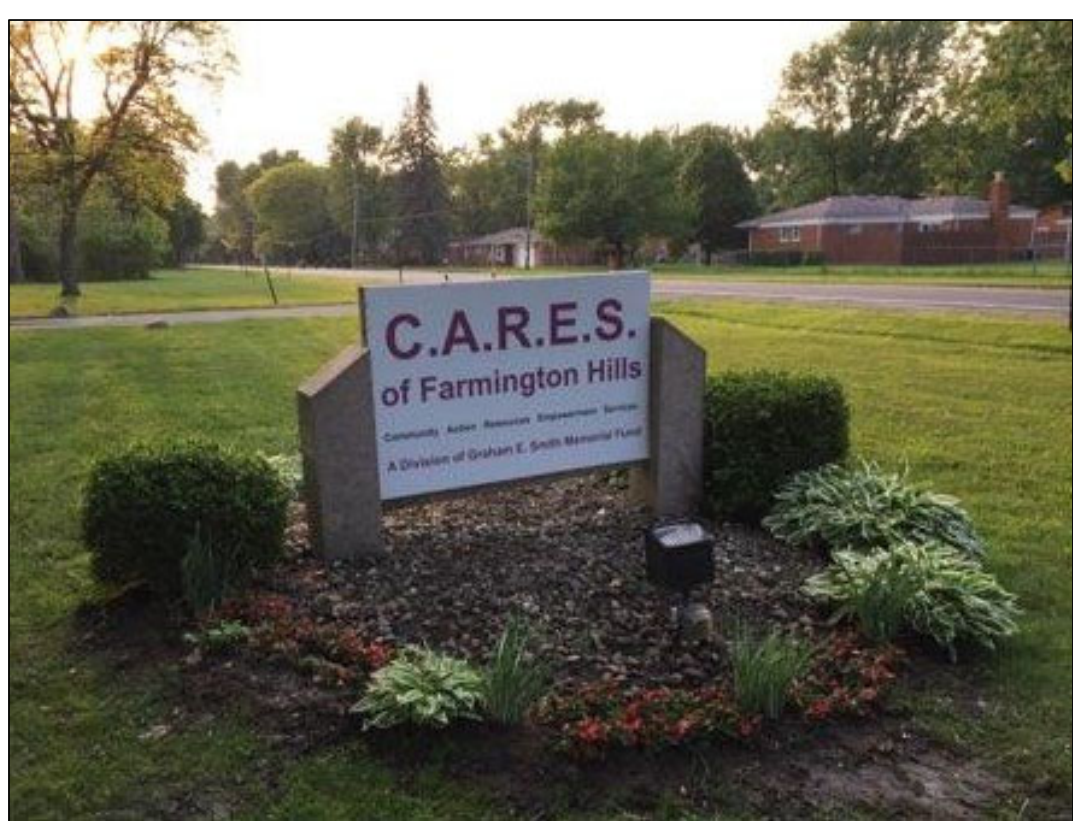

CARES of Farmington Hiills is a front-line food pantry that serves nine cities in Michigan.

(Photo by Thomas Schoenfeldt/CARES of Farmington Hills) 
stocked store where families with a Bridge Card can shop and get less costly prices so their food dollars go further, and hopefully that means healthier eating. This is the first store of this type in the state of Michigan, and it officially opened on August 3, 2020. It has been exciting to see the response of the shoppers and how grateful they are. Any profits that might be made from the store will be used to help supply food for the free pantry.

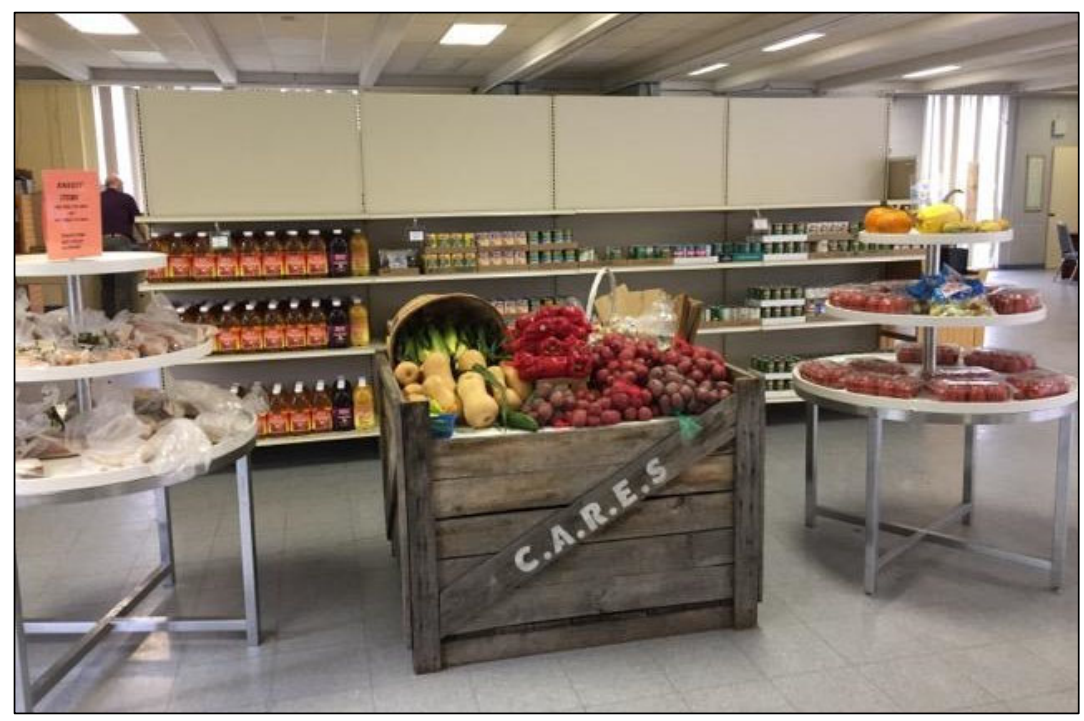

CARES's client choice food pantry prior to the pandemic.

(Photo by Thomas Schoenfeldt/CARES of Farmington Hills)

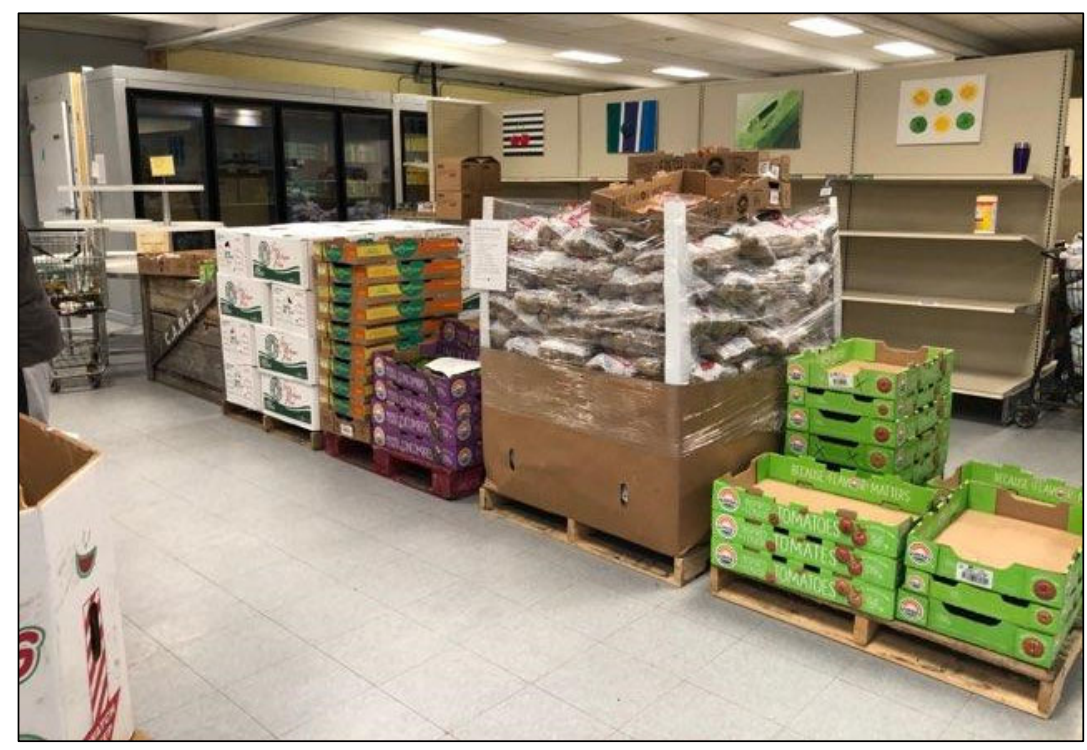

CARES's client choice food pantry after the pandemic.

(Photo by Thomas Schoenfeldt/CARES of Farmington Hills)
We are looking forward to being able to restore the client-choice pantry once we are through the pandemic, and then allowing the shoppers to get their free food and then going into the store and using their other funds to purchase good food. We are trusting that this store will be a real service to the community and those in need.

This pandemic has been a real learning experience for everyone, and all the team members were very flexible and very responsive to the needs of CARES. As a result, we were able to handle all the increased requirements.

Also, during the pandemic one of the local food banks had a mobile food pantry set up in our parking lot once or twice a month. The distribution food numbers listed previously do not include any food distributed by the pop-up mobile food bank pantries. CARES provided volunteers at the mobile pantries to help manage the flow of the traffic and moving the food as needed.

A cooperative effort at many levels helped meet the needs of many of our guests during this time of highly increased needs. 